\title{
Physicochemical studies on ion-pair amphiphiles: Solution and interfacial behaviour of systems derived from sodium dodecylsulfate and $n$-alkyltrimethylammonium bromide homologues
}

\author{
KAJARI MAITI ${ }^{1}$, SUBHASH C BHATTACHARYA ${ }^{1}$, SATYA P MOULIK ${ }^{1}$ and \\ AMIYA K PANDA ${ }^{2, *}$ \\ ${ }^{1}$ Centre for Surface Science, Department of Chemistry, Jadavpur University, Kolkata 700032 \\ ${ }^{2}$ Department of Chemistry, University of North Bengal, Darjeeling 734013 \\ e-mail: akpanda1@yahoo.com
}

MS received 23 March 2010; revised 13 May 2010; accepted 19 May 2010

\begin{abstract}
Bulk and interfacial properties of ion-pair amphiphiles (IPA), formed between sodium dodecylsulfate (SDS) and $n$-alkyltrimethylammonium bromide homologues $\left(\mathrm{C}_{n} \mathrm{TAB} ; n=10,12,14,16\right.$, and 18), have been investigated. Different phases and aggregated states, formed in the ternary combinations of $\mathrm{C}_{\mathrm{n}} \mathrm{TAB} / \mathrm{SDS} / \mathrm{H}_{2} \mathrm{O}$, have been identified and described. Equimolar mixture of IPAs in water yielded precipitates, in the form of coacervates. Aqueous solubility of isolated coacervates in presence and absence of additives like cholesterol and bile salts have been examined. The isolated coacervates have been characterized by ${ }^{1} \mathrm{H}$ NMR, FTIR, X-ray diffraction (XRD), differential scanning calorimetry (DSC) and polarization microscopic measurements. The coacervates have appeared in the shape of needle and complex flower-like aggregates. Surface pressure $(\pi)$-area (A) isotherm of the coacervates at the air/water interface have been constructed and compared with the lipid 1,2-dipalmitoyl-sn-glycero-3phosphocholine (DPPC). Morphologies of the IPA monolayers at different surface pressures have been also examined by epifluorescence microscopy. The compressed interfacial monolayers have produced spherical (both regular and irregular) and fern-leaf like domains.
\end{abstract}

Keywords. IPA/catanionic; monolayer; film morphology.

\section{Introduction}

Ternary systems comprising water, cationic and anionic surfactants can exhibit arrays of self-assembled microstructures, viz. micelles, vesicles, planar bilayers, bi-continuous structures, etc. Previous studies have shown that oppositely charged single tailed surfactants could associate through electrostatic attraction to mimic phospholipids-like structures under specific conditions. ${ }^{1-3}$ These ion-pair amphiphiles (IPA) resemble phospholipids and can form 'catanionic' or 'catanosomes'. The various aggregated microstructures (micelles, vesicles, and lamellar phases) of catanionic surfactants have attracted attention of researchers for their multifaceted application potentials in the field of membrane mimicking systems, drug delivery, nanoparticle synthesis, etc. ${ }^{4-10}$ Equimolar mixtures of oppositely charged surfactants in aqueous medium form insoluble IPAs,

*For correspondence known as coacervates. ${ }^{1}$ They are thus uncharged, pseudo-double chain entities each having two noncovalently attached alkyl chains to a common pair of head groups, wherein the attractive electrostatic interaction produce strong synergism. ${ }^{11}$ The products may form a number of complex microstructures, as mentioned above, compared to those exhibited by their individual components. Factors like alkyl chain lengths (especially the alkyl chain length per surfactant), total surfactant concentration, surfactant mixing ratio, and temperature control the rich array of possible aggregated structures formed. In general, these systems tend to form bilayer structures and vesicles. For coacervates, complications owing to the presence of inorganic counter-ions (usually halide and alkali metal ions) are essentially eliminated; the system thus becomes more amenable to simple modelling. It is well-known that the geometry of the surfactant molecules plays an important role on their aggregation behaviour. The critical packing parame$\operatorname{ter}^{12}\left(P_{c}\right)$ of a surfactant system decides the type of 
possible assemblies in solution. In the case of IPA, to get $P_{c}$ as the vesicle formation parameter ${ }^{13,14}$ require the effective area of the head group is not simply the summation of its precursors, the electrostatic attraction between the head groups and their reduced hydration have to be considered. Such considerations makes the IPAs preferentially form bilayer vesicles than micelles in aqueous medium.

Two-dimensional phase behaviours of insoluble IPA monolayer spread at the air/water interface are considered to mimic the behaviours of phospholipid monolayers. ${ }^{15-17}$ Although different phases can be identified at the interface but their characteristic features and structures are still the subject of intensive research. Different techniques have been employed to study the phase behaviours and the interfacial morphologies of the IPAs; they are epifluorescence, polarization and Brewster angle microscopy, etc. ${ }^{18-20}$ Besides atomic force microscopic measurements of the transferred monolayer and Langmuir-Blodgett (LB) technique have been used to understand their microstructural information. ${ }^{21,22}$

Although physicochemical studies have been made on the bulk as well as the interfacial properties of IPAs, still the efforts are considered fragmentary in nature. ${ }^{4,5,23-25}$ Although the said coacervates can mimic phospholipids, still their surface activity, aqueous solubility, vesicle forming capability, etc. have not been so far systematically investigated. Moreover, limited studies on the interfacial behaviour of the IPAs at the air/water interface are available in literature. ${ }^{15-17,26-30}$ Literature survey has been revealed that investigations on IPAs with systematic variation of the chain length of one of the components are only limited. ${ }^{31,32}$ The study of Estoe $e t a l^{31}$ of aqueous solutions containing asymmetric chain catanionics of the homologous series $n$-propylammonium to $n$-heptylammonium dodecylsulphate $\left(\mathrm{C}_{3}-\mathrm{C}_{12}\right.$ to $\left.\mathrm{C}_{7}-\mathrm{C}_{12}\right)$ has shown that the $\mathrm{CMC}$ of the catanionics decrease with increasing amine chain length where as the mean area per surfactant molecule and the mean area per hydrocarbon chain in the monolayer increase. The mean area per hydrocarbon chain of the catanioics were much lower than the parent component (SDS) which indicated strong ion pairing. Persson et $a l^{32}$ presented a systematic study of the effect on the number of carbons $\left(n_{c}\right)$ in the alkyl chain of the counterion on the phase behaviour of eight binary 1-alkylpyridinium octane-1-sulfonate (APOS)/water systems. The phase diagrams consisting of a micellar solution phase, and a liquid crystal- line phase (at higher surfactant concentrations) were observed. The mean area per molecule at the air/ solution interfaces was rather constant for all the different APOSs except for the 1-octyl-POS.

Studies on their aqueous solubility in presence of additives have also been scarcely reported. These have prompted us to investigate on the IPAs formed between sodium dodecylsulfate (SDS) and $n$-alkyltrimethylammonium bromide $\left(\mathrm{C}_{n} \mathrm{TAB}\right)$ homologues. They are expected to find potential applications in the field of membrane mimicking systems, drug delivery, nanoparticle synthesis, etc. ${ }^{4-10}$

We here report the physicochemistry of the process of coacervation between sodium dodecylsulfate (SDS) and $n$-alkyltrimethylammonium bromide homologous (cationic surfactants with hydrocarbon chains having carbon numbers 10,12, 14, 16, and 18). Their aqueous phase behaviour and characterization of their microstructures have been studied along with the aqueous solubility of the coacervates in presence of additives like cholesterols and bile salts. The coacervates have been characterized by XRD, FTIR and ${ }^{1} \mathrm{H}$ NMR techniques and their thermotropic behaviours have been investigated by DSC and polarization microscopic methods.

\section{Experimental}

\subsection{Materials}

$n$-Alkyltrimethylammonium bromides (purity $>98 \%$ ) were products of Alfa Aesar (USA) [ $n$-decyltrimethylammonium bromide $\left(\mathrm{C}_{10} \mathrm{TAB}\right), n$-dodecyltrimethylammonium bromide $\left(\mathrm{C}_{12} \mathrm{TAB}\right), n$-tetradecyltrimethylammonium bromide $\left.\left(\mathrm{C}_{14} \mathrm{TAB}\right)\right]$; Sigma (USA) [n-hexadecyltrimethylammonium bromide $\left.\left(\mathrm{C}_{16} \mathrm{TAB}\right)\right]$ and Fluka (Switzerland) [n-octadecyltrimethylammonium bromide $\left.\left(\mathrm{C}_{18} \mathrm{TAB}\right)\right]$. SDS (purity 99\%), DPPC, cholesterol, sodium cholate $(\mathrm{NaC})$ and sodium deoxycholate $(\mathrm{NaDC})(98 \% \mathrm{pu}-$ rity) and [1-palmitoyl-2-\{12-[(7-nitrobenz-2-oxa1,3-diazo-4-yl)amino] dodecanoyl $\}$-sn-glycerol-3phosphocholine] (NBD-PC, probe for epifluorescence imaging, purity $>95 \%$ ) were products from Sigma (USA). HPLC grade chloroform and methanol (SRL, India) were used to prepare solutions of IPAs, DPPC and NBD-PC. The chemicals were used as received. Doubly distilled water (specific conductance, $2-4 \mu \mathrm{S} \mathrm{cm}^{-1}$ at $303 \mathrm{~K}$ ) was used for all preparations. 


\subsection{Conductometric measurements}

Conductance measurements were taken at a frequency of $1.0 \mathrm{kHz}$ with a Jenway conductivity meter (UK) with an accuracy of $\pm 0.5 \%$ using a dip-type conductance cell of cell constant $0.92 \mathrm{~cm}^{-1}$. The temperature was maintained at $298 \mathrm{~K}$ with a Neslab RTE-100 (USA) temperature controlled circulator water bath of accuracy $\pm 0 \cdot 1 \mathrm{~K}$.

\subsection{Construction of phase diagram}

Different volumes (at a fixed weight percent, wt \%) of a particular aqueous $\mathrm{C}_{n} \mathrm{TAB}$ solution were taken in stoppered test tubes (placed in a constant temperature water bath at $298 \pm 0 \cdot 1 \mathrm{~K})$. A known volume (of same wt $\%$ as of $\mathrm{C}_{n} \mathrm{TAB}$ ) of aqueous SDS solution was progressively added under stirring condition in such a way that the $\mathrm{C}_{n} \mathrm{TAB}$ : SDS weight ratio would vary (overall wt $\%$ of surfactant mixtures would thus remain the same). On the basis of visual observations collected on more than 250 samples with varying $\mathrm{wt} \%$ of $\mathrm{C}_{n} \mathrm{TAB}$ and $\mathrm{SDS}$; phase boundaries were delineated, ${ }^{30}$ which remained unchanged over an extended period of time (30 days). Repeat experiments produced good reproducibility.

\subsection{Spectrophotometry}

Absorption measurements were taken at $255 \mathrm{~nm}$ at $298 \mathrm{~K}$ in a UV-Vis (1601) spectrophotometer (Shimadzu, Japan) using a matched pair of quartz cells of path length $1 \mathrm{~cm}$. The ion-pairs produced appreciable absorbance below and above the point of maximum solubility.

\subsection{Preparation of coacervates}

A known amount of $\mathrm{C}_{n}$ TAB solution (above the CMC) was taken in a conical flask and a stoichiometric amount of aqueous solution of SDS was added drop-wise into it so that in the final mixture the mole ratio of $\mathrm{C}_{n} \mathrm{TAB}: \mathrm{SDS}$ was $1: 1$. The white precipitate (coacervate) was extracted by chloroform. The chloroform layer was then removed by vacuum drying. The coacervate was re-dissolved in chloroform and then dried again for $24 \mathrm{~h}$ under vacuum and grounded to fine powders and stored in a desiccator. $^{16}$

\subsection{Characterization of coacervates}

2.6a ${ }^{1} H$ NMR: The ${ }^{1} \mathrm{H}$ NMR spectra of the coacervates were recorded at $298 \mathrm{~K}$ in Bruker (AC), FT-NMR spectrometer using TMS (tetramethylsilane) as the internal reference at $300 \mathrm{MHz}$ employing $\mathrm{CdCl}_{3}$. The chemical shift $(\delta)$ values are reported in parts per million (ppm).

2.6b FTIR: The Fourier transform infra red (FTIR) spectra of the coacervates as well as the precursors were taken at $298 \mathrm{~K}$ in a Perkin Elmer spectrophotometer (model-Lambda 25), USA using $\mathrm{KBr}$ as disks in the range of $4000-450 \mathrm{~cm}^{-1}$.

2.6c X-ray diffraction study: The measurements on the IPAs were taken with an automatic X-ray powder diffractometer (Ultima III, Rigaku, Japan, $\mathrm{Cu} / 40 \mathrm{kV} / 30 \mathrm{~mA}, \mathrm{~K} \beta$ filter) at room temperature $(298 \mathrm{~K})$. The data were recorded at a scan speed of $1^{\circ} \mathrm{min}^{-1}$ with a sampling width of $0.02^{\circ}$. The division and the scattering slit were kept at $2 / 3^{\circ}$ whereas the vertical divergent (restricted) and receiving slit were chosen as $10 \mathrm{~mm}$ and $0.45 \mathrm{~mm}$, respectively.

2.6d Thermal study: The thermal measurements of the coacervates were taken by two ways: (i) differential scanning calorimetry (DSC) and (ii) melting point determination.

(i) DSC: Differential scanning calorimetric measurements were performed using a Pyris 6 DSC, (Perkin Elmer, USA). The instrument was calibrated with indium before each experiment. The coacervates were then scanned at a heating rate of $5 \mathrm{~K} \mathrm{~min}^{-1}$ from $295-473 \mathrm{~K}$. The heating runs were followed by cooling runs at the same rate as that of heating. ${ }^{33}$

(ii) Melting point: The melting points of the coacervates as well as their precursors were determined in a melting point apparatus (Toshniwal, India) with an increasing temperature rate of $0.5 \mathrm{~K} \mathrm{~min}^{-1}$.

2.6e Morphology study (light polarizing microscopy): The morphology and texture of the solid crystalline phases of the coacervates were observed under a polarizing microscope (Nikon ECLIPSE LV100POL, Japan) equipped with a CCD camera. The coacervates (doped with $1 \mathrm{~mol} \%$ NBD-PC) dissolved in chloroform-methanol solution $(3: 1, \mathrm{v} / \mathrm{v})$, was dropped onto a glass slide using a Hamilton 
(USA) microsyringe and vacuum dried for $1 \mathrm{~h}$, after which images of the solid crystalline phases were taken.

2.6f Surface pressure ( $\pi$ )-area (A) isotherm: The $\pi-A$ isotherms of the coacervates and DPPC monolayer at the air/water interface were obtained in a teflon-bar-barrier type Langmuir-Blodgett Trough of dimension $30 \times 15 \mathrm{~cm}$ (model-2004C, Apex Ins. Co, India). Double distilled water (resistivity $=18.2 \mathrm{M} \Omega \mathrm{cm}$ ) was used as the sub-phase. The temperature was controlled at $298 \pm 1 \mathrm{~K}$. Coacervate or DPPC, dissolved in chloroformmethanol $(3: 1, \mathrm{v} / \mathrm{v})$, was spread with a $25 \mu \mathrm{L}$ microsyringe (Hamilton, USA) at the air/water interface. ${ }^{16,34}$ After 30 min (for the evaporation of solvent and equilibration of monolayer), the monolayer was compressed with a speed of $7.5 \mathrm{~cm}^{2} \mathrm{~min}^{-1}$. A series of compression-expansion cycles of the monolayer film at the air/water interface were performed with the same speed.

2.6g Epifluorescence microscopy: An epifluorescence microscope (model: AE31, Motic, Hong Kong) was used to take the NBD-PC doped coacervate or DPPC monolayer at different surface pressures in the Langmuir surface balance. The NDBPC doped coacervate or DPPC monolayer was excited using proper filter $(\lambda=470 \mathrm{~nm})$ and the emission light was in the green region $(\lambda=530 \mathrm{~nm}){ }^{35}$ The images of the compressed monolayer with the formed domains at varied surface pressure were recorded with a digital camera attached to the microscope.

\section{Results and discussion}

\subsection{Nature of interaction}

3.1a Conductance behaviour of mixed surfactant systems: As $\mathrm{C}_{n} \mathrm{TAB}$ and SDS are oppositely charged, they were expected to undergo strong electrostatic interaction and the formed ion-pair would assemble forming different phases in the medium. Conductometry could conveniently monitor the process. The observed results are summarized in table 1 .

In the conductometric titration of $\mathrm{C}_{n} \mathrm{TAB}$ with SDS, $\mathrm{C}_{n} \mathrm{TAB}$ solutions below and above their $\mathrm{CMCs}$ were taken in the double walled glass container at $298 \mathrm{~K}$ and SDS solution of known strength was then added step-wise and conductance values were recorded at a regular time intervals; the visual observations of the solution conditions were also noted. Little addition of SDS into the solution of $\mathrm{C}_{n} \mathrm{TAB}$ resulted in the appearance of turbidity. With the further addition of SDS, the solution became clear. The break points observed in the specific conductance $(\kappa)$ vs $[\mathrm{SDS}] /\left[\mathrm{C}_{n} \mathrm{TAB}\right]$ plot corresponded to different phases formed in the system. When conductometric titrations were performed using $\mathrm{C}_{n} \mathrm{TAB}$ at below their CMC $\left(\left[\mathrm{C}_{\mathrm{n}} \mathrm{TAB}\right]=0.2 \mathrm{mmol} \mathrm{\textrm {dm } ^ { - 3 }}\right)$, a sharp break point appeared at equimolar ratio with a second break at a much higher concentration (the solution then visually became clear). The appearance of the second break increased linearly with the alkyl chain length of $\mathrm{C}_{n} \mathrm{TAB}$ with a correlation coefficient, $R=0.999$. The solubility of the coacervates decreased with increasing $C_{n}$ and hence larger amounts of SDS were needed for their solubilization. When the cationic surfactants were taken above their CMCs, the titration patterns became complex. For $C_{10}$ and $C_{18}$, the first break appeared nearly at equimolar ratio. The second break, appeared on the onset of formation of clear solution, linearly increased with alkyl chain length up to $C_{16}$, and then it abruptly rose for $C_{18}$. At the first break, a transition from micelle to vesicle started and continued up to the second break with a probable morphological change like vesicle expansion. Safran et $a l^{36}$ proposed a model for thermodynamic stability of spontaneous vesicle formation assuming non-ideal mixing of surfactants. While performing the conductometric titrations using $16 \mathrm{mmol} \mathrm{dm}{ }^{-3} \mathrm{C}_{n} \mathrm{TAB}$, two break points appeared prior to the equimolar ratio for $n=12$ and 14. Similar features were obtained when $\kappa$ values were plotted against total surfactant concentration ([S $\left.S_{\text {total }}\right]$ ) (as shown in figure 1$)$. For $C_{12}$

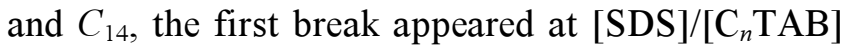
ratios of $0.85: 1$ and $0.28: 1$, respectively; the second break occurred at $[\mathrm{SDS}] /\left[\mathrm{C}_{n} \mathrm{TAB}\right]$ ratios $1 \cdot 2: 1$ and $1.0: 1$, respectively. Further addition of SDS resulted in the formation of a gel state, which again got destabilized and became clear fluid at higher mole ratios (2.5 for $\mathrm{C}_{12} \mathrm{TAB}-\mathrm{SDS}$ system). In the cases of $C_{10}$ and $C_{12}$, we observed gel formation (at $[\mathrm{SDS}] /\left[\mathrm{C}_{n} \mathrm{TAB}\right]$ ratios $1.5: 1$ and $1.9: 1$, respectively) and its transformation into clear solution at higher $[\mathrm{SDS}] /\left[\mathrm{C}_{\mathrm{n}} \mathrm{TAB}\right]$ ratios $(2.1: 1$ and 2.5:1, respectively). The internal events and changes in such systems are interesting but less clear. Appearance of two break points have also been previously 
Table 1. $\mathrm{SDS} / \mathrm{C}_{n} \mathrm{TAB}^{\mathrm{a}, \mathrm{b}}$ mole ratio dependent conductance behaviour during the titration of $\mathrm{C}_{n} \mathrm{TAB}$ by SDS in aqueous medium at $298 \mathrm{~K}$.

\begin{tabular}{lll}
\hline & \multicolumn{2}{c}{ Breaks at $[\mathrm{SDS}] /\left[\mathrm{C}_{n} \mathrm{TAB}\right]$} \\
\cline { 2 - 3 }$n$ & {$\left[\mathrm{C}_{n} \mathrm{TAB}\right]<\mathrm{CMC}$} & \multicolumn{1}{c}{$\left[\mathrm{C}_{n} \mathrm{TAB}\right]>\mathrm{CMC}$} \\
\hline 10 & $1 \cdot 07,12 \cdot 0(\mathrm{c})$ & $0 \cdot 95,1 \cdot 49(\mathrm{~g}), 2 \cdot 13(\mathrm{c})$ \\
12 & $0 \cdot 99,13 \cdot 6(\mathrm{c})$ & $0 \cdot 85,1 \cdot 18,1 \cdot 89(\mathrm{~g}), 2 \cdot 51(\mathrm{c})$ \\
14 & $1 \cdot 05,15 \cdot 4(\mathrm{c})$ & $0 \cdot 28,1 \cdot 02,3 \cdot 22(\mathrm{c})$ \\
16 & $0 \cdot 91,16 \cdot 8(\mathrm{c})$ & $0 \cdot 84,3 \cdot 56(\mathrm{c})$ \\
18 & $0 \cdot 90,18 \cdot 6(\mathrm{c})$ & $0 \cdot 90,15 \cdot 1(\mathrm{c})$ \\
\hline
\end{tabular}

${ }^{\mathrm{a}} \mathrm{c}$ : clear solution started forming; $\mathrm{g}$ : gel formation started.

${ }^{\mathrm{b}} \mathrm{CMC}\left(\mathrm{mmol} \mathrm{dm}^{-3}\right)$ of SDS, C 10 TAB, C 12 TAB, C $\mathrm{C}_{14} \mathrm{TAB}, \mathrm{C}_{16} \mathrm{TAB}$ and $\mathrm{C}_{18} \mathrm{TAB}$ at $303 \mathrm{~K}$ are $7 \cdot 7^{44}, 66^{44}, 15^{44}, 3 \cdot 6^{44}, 0 \cdot 93^{44}$, and $0 \cdot 3^{39}$, respectively

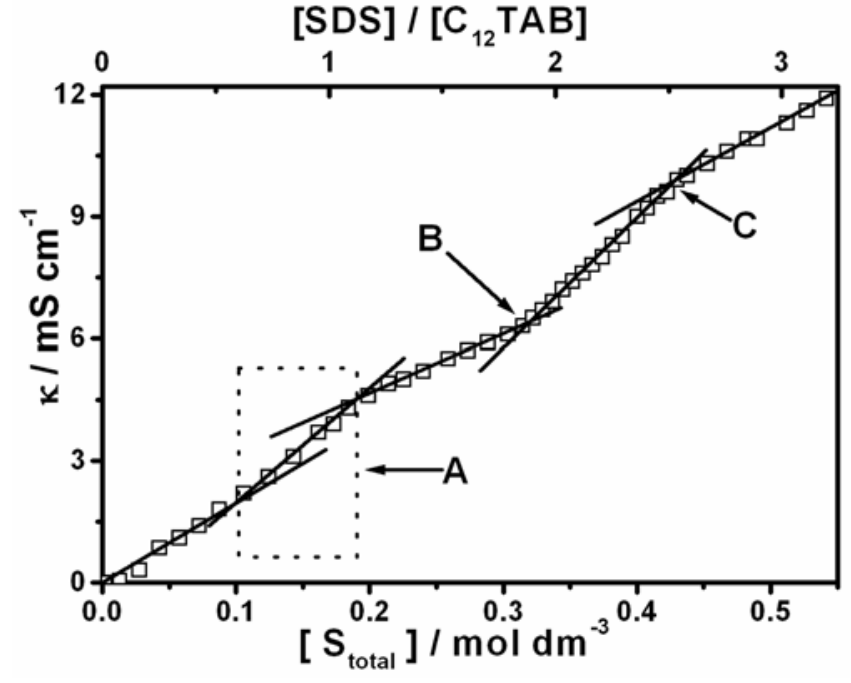

Figure 1. Conductance vs. total surfactant concentration profile during the titration of $\mathrm{C}_{12} \mathrm{TAB}$ with $\mathrm{SDS}$ in aqueous medium at $298 \mathrm{~K}$. $\left[\mathrm{C}_{12} \mathrm{TAB}\right]=16 \times 10^{-3} \mathrm{~mol} \mathrm{dm}^{-3}$. Sections: A, coacervate formation $\left(0 \cdot 10-0 \cdot 19 \mathrm{~mol} \mathrm{dm}^{-3}\right)$; $\mathrm{B}$, onset of formation of gel $\left(0.32 \mathrm{~mol} \mathrm{dm}^{-3}\right)$; and $\mathrm{C}$, onset of formation of clear solution $\left(0.42 \mathrm{~mol} \mathrm{dm}^{-3}\right)$. $[\mathrm{SDS}] /\left[\mathrm{C}_{12} \mathrm{TAB}\right]$ values: $\mathrm{A}(0 \cdot 85-1 \cdot 18) ; \mathrm{B}(1.89)$ and $\mathrm{C}$ $(2 \cdot 51)$.

reported due to the formation of mixed vesicles where the curvatures of the monolayer were responsible for the effect of micelle to vesicles or vesicles to micelles transition. ${ }^{37}$

3.1b Phase behaviour of $\mathrm{C}_{n} \mathrm{TAB} / \mathrm{SDS} / \mathrm{H}_{2} \mathrm{O}$ systems: The interaction registered through conductometric titrations indicated the formation of different phases and assemblies in solution which was intimately examined. Figure 2 illustrates the multiplicity of phases formed at $298 \mathrm{~K}$ in the ternary system of water, SDS and $\mathrm{C}_{n} \mathrm{TAB}$. Table 2 presents composi- tions of the phases obtained (in wt \%) for all the five studied combinations. The tabulations represent observations from several samples after equilibration for one month. Most combinations got equilibrated within a week but vesicles/viscous/multiphase (consisting of three phases, two liquid phases separated by a solid phase) required longer equilibration time $(\sim 15$ days $) .{ }^{2,38}$ The dilute surfactant region in the illustration has a maximum total surfactant share of $5 \mathrm{wt} \%$. The ternary phase diagram for the asymmetric surfactant chain lengths combinations of $\mathrm{C}_{18} \mathrm{TAB}$ and SDS with water is depicted in figure $\mathrm{S} 1$ in the supplementary section.

The $\mathrm{C}_{n} \mathrm{TAB}$ and SDS corners were rich in the micellar phase and its percentage was more or less same for $C_{10}$ and $\mathrm{C}_{12} \mathrm{TAB}$ but decreased gradually with the increase in $\mathrm{C}_{n} \mathrm{TAB}$ alkyl chain length. The percent clear solution with precipitate produced a maximum for $\mathrm{C}_{14} \mathrm{TAB} / \mathrm{SDS} / \mathrm{H}_{2} \mathrm{O}$ system; when plotted against $n$, a $2^{\circ}$ polynomial equation with a correlation coefficient of 0.999 was obtained (see supplementary part). The region of turbid solution with precipitate gave a minimum for $\mathrm{C}_{12} \mathrm{TAB} /$ $\mathrm{SDS} / \mathrm{H}_{2} \mathrm{O}$ system, followed by a gradual increase that fitted to a two degree polynomial equation with $R^{2}=0.983$ (see supplementary (figure $\mathrm{S} 2$ )). The $\mathrm{wt} \%$ multiphase region observed was maximum for $\mathrm{C}_{10} \mathrm{TAB} / \mathrm{SDS} / \mathrm{H}_{2} \mathrm{O}$ system. But no multiphase region was found to form for $\mathrm{C}_{18} \mathrm{TAB} / \mathrm{SDS} / \mathrm{H}_{2} \mathrm{O}$ system. Clear gel region was formed for $\mathrm{C}_{10}$ and $\mathrm{C}_{12}$ representatives and turbid gel was found to appear only for the latter. The $\mathrm{C}_{12} \mathrm{TAB} / \mathrm{SDS} / \mathrm{H}_{2} \mathrm{O}$ system produced maximum variety of phases. The complexity of the phases gradually decreased with alkyl chain length of $\mathrm{C}_{n} \mathrm{TAB}$. Herrington et $a l^{2}$ also studied $\mathrm{C}_{12} \mathrm{TAB} / \mathrm{SDS} / \mathrm{H}_{2} \mathrm{O}$ system at $298 \mathrm{~K}$ but they did not find any multiphase or gel region; we obtained the 
Table 2. Composition/abundance of different phases ${ }^{\mathrm{a}}$ obtained for $\mathrm{C}_{n} \mathrm{TAB} / \mathrm{SDS} / \mathrm{H}_{2} \mathrm{O}$ systems at $298 \mathrm{~K}$.

\begin{tabular}{|c|c|c|c|c|c|c|}
\hline \multirow[b]{2}{*}{$\begin{array}{l}\mathrm{C}_{n} \mathrm{TAB} / \mathrm{SDS} / \mathrm{H}_{2} \mathrm{O} \\
n\end{array}$} & \multicolumn{6}{|c|}{$\mathrm{Wt} \%$ composition of different phases } \\
\hline & Micelle & $\begin{array}{c}\text { Clear solution }+ \\
\text { precipitate }\end{array}$ & $\begin{array}{l}\text { Turbid solution }+ \\
\text { precipitate }\end{array}$ & Multiphase & Clear gel & Turbid gel \\
\hline 10 & $40 \cdot 7$ & $2 \cdot 30$ & $28 \cdot 8$ & $11 \cdot 1$ & $17 \cdot 1$ & - \\
\hline 12 & $40 \cdot 8$ & $36 \cdot 7$ & $14 \cdot 8$ & $0 \cdot 30$ & $2 \cdot 88$ & $4 \cdot 44$ \\
\hline 14 & $25 \cdot 0$ & $51 \cdot 6$ & $23 \cdot 3$ & $0 \cdot 15$ & - & - \\
\hline 16 & $17 \cdot 3$ & $46 \cdot 6$ & $34 \cdot 5$ & 1.60 & - & - \\
\hline $18^{\mathrm{a}}$ & $4 \cdot 00$ & $20 \cdot 0$ & $76 \cdot 0$ & - & - & - \\
\hline
\end{tabular}

${ }^{\mathrm{a}} \mathrm{For} \mathrm{C}_{18} \mathrm{TAB} / \mathrm{SDS} / \mathrm{H}_{2} \mathrm{O}$ system, the dilute surfactant region illustrated has a maximum total surfactant composition of $0 \cdot 1 \mathrm{wt} \%$ (because of low aqueous solubility of $\mathrm{C}_{18} \mathrm{TAB}$ at $298 \mathrm{~K}$ )

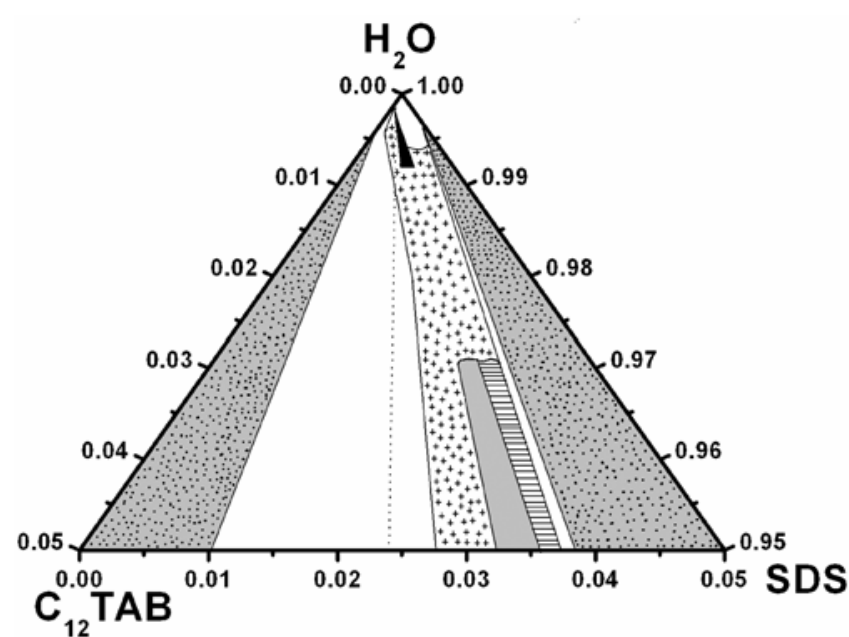

Figure 2. Ternary phase diagram of $\mathrm{C}_{12} \mathrm{TAB} / \mathrm{SDS} / \mathrm{H}_{2} \mathrm{O}$ system at $298 \mathrm{~K}$. Regions: Dotted-shade-micelle; unmarked zone - clear solution with precipitate; cross marked zone - turbid solution with precipitate; gray shed - turbid gel; horizontal parallel lines - clear gel; black - multiphase; broken line - equimolar composition.

gel regions (both clear and turbid) in the $\mathrm{C}_{12} \mathrm{TAB} / \mathrm{SDS} / \mathrm{H}_{2} \mathrm{O}$ ternary phase diagram which they had presented as the unresolved region.

\subsection{Coacervate characterization}

The main aspect of interaction between SDS and $\mathrm{C}_{n} \mathrm{TAB}$ (observed in the phase study) was the formation of the coacervates $\left(\mathrm{C}_{n} \mathrm{TA}^{+} \mathrm{DS}^{-}\right)$. The coacervates were isolated and examined in detail. Their characterization is described below. The spontaneously formed coacervates by mixing equimolar oppositely charged surfactant solutions can be represented as below:

$$
\begin{aligned}
& \stackrel{\omega}{\mathrm{C}} \mathrm{H}_{3}\left(\mathrm{CH}_{2}\right)_{x} \stackrel{\gamma}{\mathrm{C}} \mathrm{H}_{2} \stackrel{\beta}{\mathrm{C}} \mathrm{H}_{2} \stackrel{\alpha}{\mathrm{C}} \mathrm{H}_{2}\left(\mathrm{CH}_{3}\right)_{3} \stackrel{+}{\mathrm{N}} \mathrm{Br}^{-} \\
& +\stackrel{\omega^{\prime}}{\mathrm{C}} \mathrm{H}_{3}\left(\mathrm{CH}_{2}\right)_{8} \stackrel{\gamma^{\prime}}{\mathrm{C}} \mathrm{H}_{2} \stackrel{\beta^{\prime}}{\mathrm{C}} \mathrm{H}_{2} \stackrel{\alpha^{\prime}}{\mathrm{C}} \mathrm{H}_{2} \mathrm{O}\left(\mathrm{O}_{3}\right) \stackrel{-}{\mathrm{S}} \mathrm{Na}^{+} \\
& \Leftrightarrow \stackrel{\omega}{\mathrm{C}} \mathrm{H}_{3}\left(\mathrm{CH}_{2}\right)_{x} \stackrel{\gamma}{\mathrm{C}} \mathrm{H}_{2} \stackrel{\beta}{\mathrm{C}} \mathrm{H}_{2} \stackrel{\alpha}{\mathrm{C}} \mathrm{H}_{2}\left(\mathrm{CH}_{3}\right)_{3} \\
& \stackrel{+-}{\mathrm{N}}\left(\mathrm{O}_{3}\right) \stackrel{\alpha^{\prime}}{\mathrm{O}} \underset{\mathrm{C}}{\mathrm{C}} \mathrm{H}_{2} \stackrel{\beta^{\prime}}{\mathrm{C}} \mathrm{H}_{2} \stackrel{\gamma^{\prime}}{\mathrm{CH}_{2}}\left(\mathrm{CH}_{2}\right)_{8} \stackrel{\omega^{\prime}}{\mathrm{C}} \mathrm{H}_{3} \downarrow+\mathrm{NaBr} \text {, }
\end{aligned}
$$

where $x=6,8,10,12$ and 14 .

3.2a ${ }^{1} \mathrm{H}$ NMR of the ion-pair amphiphile of general formula $\mathrm{C}_{n} \mathrm{TA}^{+} \mathrm{DS}^{-}$: The ${ }^{1} \mathrm{H}$ NMR spectra of the formed coacervates also revealed some characteristic features. The terminal $\omega^{\prime}, \omega-\mathrm{CH}_{3}$ protons of all the IPAs showed a triplet at about $0.88 \mathrm{ppm}$ except for $\mathrm{C}_{12} \mathrm{TA}^{+} \mathrm{DS}^{-}$, which showed the same at $0.86 \mathrm{ppm}$. The $\alpha-\mathrm{CH}_{2}$ protons and methyl protons of trimethylammonium group of $\mathrm{C}_{18} \mathrm{TA}^{+} \mathrm{DS}^{-}$produced an upfield shift of $\sim 0.2$ and $0.14 \mathrm{ppm}$ with respect to the pure cationic surfactant $\left(\mathrm{C}_{18} \mathrm{TAB}\right)^{39}$ at the same molar concentration which arose due to changes in the electrostatic field in these surfactants (as $\mathrm{Br}^{-}$of $\mathrm{C}_{18}$ TAB was replaced by $\mathrm{DS}^{-}$). ${ }^{33,40}$ As the other protons were far away from the head groups, no observable changes could be found after coacervation. The $\delta$ values in case of $\mathrm{C}_{12} \mathrm{TA}^{+} \mathrm{DS}^{-}$were different from others because of matching of the hydrophobic chain lengths of the cationic and the anionic coacervate components. Similar ${ }^{1} \mathrm{H}$ NMR results were obtained for $\mathrm{C}_{16} \mathrm{TA}^{+} \mathrm{DS}^{-}$at $298 \mathrm{~K}$ by Tomasic et $a l^{33}$ where they obtained an upfield shift of ca. $0.2 \mathrm{ppm}$ with respect to the pure $\mathrm{C}_{16} \mathrm{TAB}$ and SDS at the same molar concentration (details given in the supplementary section (table $\mathrm{S} 1$ )). 
3.2b FTIR measurements: The FTIR study of the coacervates and the precursors showed that the symmetric and asymmetric $\mathrm{C}-\mathrm{H}$ stretching frequencies of the coacervates were more or less at the same position as that of the precursors; but the symmetric $(\mathrm{S}-\mathrm{O})$ and asymmetric $\left(\mathrm{N}-\mathrm{CH}_{3}\right)$ stretching frequencies of the coacervates were shifted to $\sim 24 \mathrm{~cm}^{-1}$ lower and $\sim 20 \mathrm{~cm}^{-1}$ higher frequencies, respectively than that of the pure components. This was resulted due to the size and the charge density difference between $\mathrm{Na}^{+}$and the alkyltrimethylammonium ion in the IPA, as the latter replaced the former. FTIR spectra of all the coacervates were more or less similar irrespective of the alkyl chain length. The FTIR data indicated the formation of only ionic bonds for IPA (for further details, see the supplementary part (table S2)). Tomasic et $a l^{33}$ also reported similar FTIR results of $\mathrm{C}_{16} \mathrm{TA}^{+} \mathrm{DS}^{-}$at $298 \mathrm{~K}$ where the symmetric $(\mathrm{S}-\mathrm{O})$ and asymmetric $\left(\mathrm{N}-\mathrm{CH}_{3}\right)$ stretching frequencies of the coacervates were shifted to $\sim 23 \mathrm{~cm}^{-1}$ lower and $\sim 10 \mathrm{~cm}^{-1}$ higher frequencies, respectively than that of SDS and $\mathrm{C}_{16} \mathrm{TAB}$.

3.2c XRD measurements: Characteristic portion of the X-ray diffraction patterns of the coacervate $\left(\mathrm{C}_{12} \mathrm{TA}^{+} \mathrm{DS}^{-}\right)$at $298 \mathrm{~K}$ is illustrated in figure 3 . The diffused diffraction pattern of the IPAs indicated the presence of several polymorphs or disturbances in the long 3D order. This might be the reason for the second order transition of the IPAs appeared in the DSC study (presented later).

The molecules having long hydrocarbon chains generally crystallize in layers with saturated parts of the hydrocarbon chains in trans-configuration with a

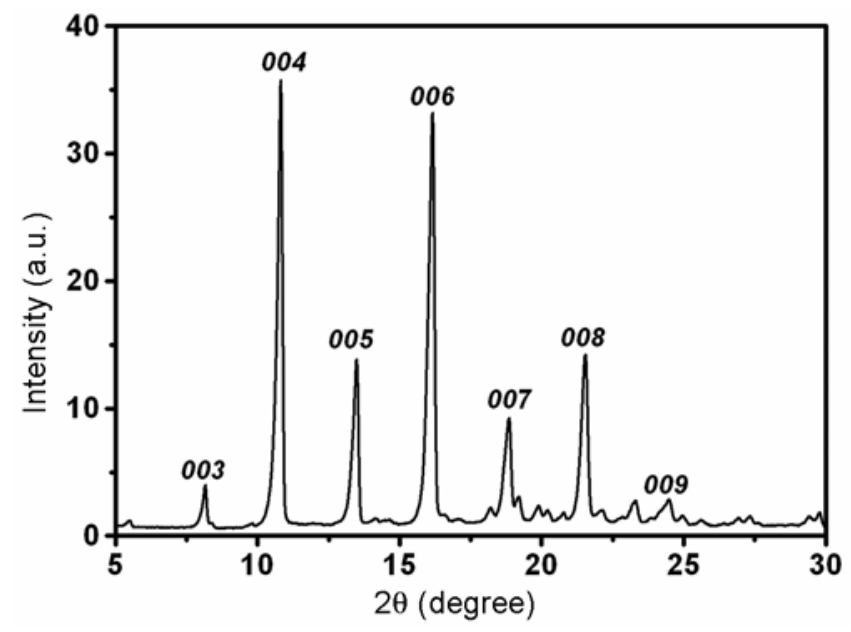

Figure 3. Powder XRD pattern of $\mathrm{C}_{12} \mathrm{TA}^{+} \mathrm{DS}^{-}$at $298 \mathrm{~K}$. high degree of molecular parallelism. ${ }^{33}$ All the compounds gave a number of diffraction lines with detectable intensities. These lines corresponded to that as diffracted from the crystal planes designated by Miller indices 00l. These types of diffraction were expected from the crystal planes corresponding to the basic lamellar thickness (with long spacing). The other diffraction lines of Miller indices $h k 0$ or $h k l$ were small in number and their intensities were also negligible. The changed positions and relative intensities of the $00 \mathrm{l}$ diffraction lines and other lines $(h k l / h k 0)$ with change in the alkyl chain length of the IPAs arose from the contribution of the alkyl part in the crystal lattice. At room temperature $(298 \mathrm{~K})$, the Bragg angle $(\Delta 2 \theta)$ between two consecutive $00 l$ diffraction lines was found to be $2.84^{\circ}$, $2.68^{\circ}, 2.52^{\circ}, 2.36^{\circ}$, and $2.20^{\circ}$ for $C_{10}, C_{12}, C_{14}, C_{16}$ and $C_{18} \mathrm{TA}^{+} \mathrm{DS}^{-}$respectively. The solid crystalline $\mathrm{C}_{n} \mathrm{TA}^{+} \mathrm{DS}^{-}$showed a systematic change in Bragg angles which corresponded to the lamellar structure. The average $\Delta 2 \theta$ increased linearly (with regression factor $=1.000$ ) with decrease in alkyl chain length of $\mathrm{C}_{n} \mathrm{TAB}$. For $C_{12}, 004$ diffraction line had the maximum intensity whereas the 006 diffraction line was the maximum intensity peak for $C_{14}$ and $C_{16}$; for $C_{10}$ and $C_{18}$, the maximum intensity peak was other than $00 l$ type. In spite of the ordering observed in the crystal pattern of the coacervates, a disordered phase was also present at the room temperature. Tomasic et $a l^{33,41}$ had shown that as temperature increased, the crystal lattice of $\mathrm{C}_{16} \mathrm{TA}^{+} \mathrm{DS}^{-}$became much more ordered as different coexisting form of bilayers were converted into one form and thermal energy needed for that purpose was used to overcome the steric hindrance created by the molecular conformation changes by the alkyl groups at the lamella-lamella interface. The two key factors which contributed to the close packing of the catanionics were the electrostatic interaction between the two oppositely charged head groups, and the intensity of hydrophobic interaction between the alkyl chains; the higher the van der Waals interaction between the hydrophobic chains, stronger was the close packing forces. According to Tomasic et $a l^{3,41}$ the bilayers containing IPA having two head groups should be separated by two paraffinic layers in which equimolar mixing of the alkyl chains of the cationic and anionic surfactants occurs. Inter lamellar electrostatic interactions between two oppositely charged head groups neutralized the surface charge density and thus helped in forming closely packed ion-pairs. The electrostatic force produced was much stronger 
than the van der Waals force. The molecules were more densely packed because the area per molecule was lowered through electrostatic attraction. Systematic shift of the $00 \mathrm{l}$ diffraction lines of the crystalline phase toward smaller Bragg angles and changes in positions and intensities of the diffraction lines with decreasing alkyl chain length proved that though electrostatic force was much stronger than the van der Waals force, the latter also played an important role since only the alkyl chain length of $\mathrm{C}_{n} \mathrm{TAB}$ was varied keeping the head groups nonvariant.

3.2d Thermal study: DSC study: Figure 4 represents the thermogram of $\mathrm{C}_{n} \mathrm{TA}^{+} \mathrm{DS}^{-}$; they exhibited several endothermic heating peaks and exothermic cooling peaks. Two important endothermic transitions (i) transition from solid-liquid crystalline phase $\left(T_{l c}\right)$ and (ii) melting of the coacervate $\left(T_{m}\right)$ were observed in the thermogram. All the coacervates formed smectic liquid crystalline phase between $T_{l c}$ and $T_{m}$. The enthalpy changes for the first order transitions were calculated from the peaks. The entropy changes in the transitions indicated ordering in the systems. In the heating cycle at $308 \mathrm{~K}$, $\mathrm{C}_{n} \mathrm{TA}^{+} \mathrm{DS}^{-}$produced a second order transition like amorphous and semi-crystalline organic polymers; ${ }^{33}$ corresponding exothermic peak was not observed during cooling. The next observed transitions were two sharp partially resolved maxima (for $n \geq 14$ ) and also two sharp endothermic peaks in the temperature range of $353-357 \mathrm{~K}$. The endothermic solid crystalline-liquid crystalline phase transitions $\left(T_{l c}\right)$ for the

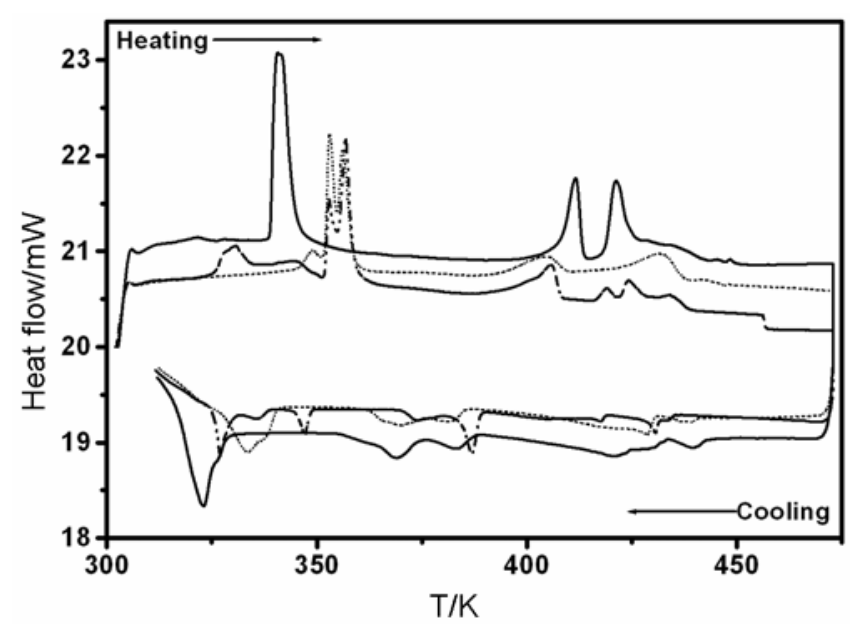

Figure 4. DSC thermogram of different IPAs. $\mathrm{C}_{12} \mathrm{TA}^{+} \mathrm{DS}^{-}:-; \mathrm{C}_{14} \mathrm{TA}^{+} \mathrm{DS}^{-}$: .....; ; and $\mathrm{C}_{18} \mathrm{TA}^{+} \mathrm{DS}^{-}:$...Heating and cooling rate $5 \mathrm{~K} \mathrm{~min}^{-1}$.
IPAs were lower $(\sim 340 \mathrm{~K})$ for $n \leq 12$, and gave more or less constant value (353-357 K) for higher $n$ values. The related enthalpy changes also followed the same order i.e. constant values $\left(\sim 15.3 \mathrm{~kJ} \mathrm{~mol}^{-1}\right)$ up to $n=12$; then increased suddenly and became constant with increasing $\mathrm{n}$. The transitions during cooling were at lower temperatures compared to those observed during heating; i.e. a phenomenon of hysteresis arose. The temperature corresponded to the melting transition were found to be following the reverse order as observed in case of $T_{l c}$, it was about $422 \mathrm{~K}$ for $n \leq 12$; with further increase in $n$, it decreased and gave same values $(\sim 405 \mathrm{~K})$. But the enthalpy changes associated with $T_{m}$ had shown interesting feature; it initially decreased with $C_{n}$ up to $n=12$, gave the minimum for $\mathrm{C}_{14} \mathrm{TA}^{+} \mathrm{DS}^{-}$, then again increased (followed a $3^{\circ}$ polynomial equation with $\left.R^{2}=0.957\right)$. The endothermic transition at $423 \mathrm{~K}$ was not observed during cooling. Tomasic et $a l^{33}$ showed that for $\mathrm{C}_{16} \mathrm{TA}^{+} \mathrm{DS}^{-}$, two endothermic peaks at 443 and $448 \mathrm{~K}$ corresponded to the solid to liquid crystalline, and liquid crystalline to isotropic phase transitions, respectively, and the enthalpy change during melting was higher than that of isotropic phase transition. But, our findings were not matched with their result and the enthalpy change for melting was lower than that for the phase transition from solid-liquid crystalline (further details are given in the supplementary part).

We considered that during heating, two processes simultaneously occurred: (i) a disordered/ordered transition in the solid phase, and (ii) a transition of the solid to the liquid crystalline state. The changes in the molecular orientations caused increase in rotation of the hydrocarbon moiety. At the melting point, the long-range order in the system disappeared. Different phase-transition kinetics was involved for heating and cooling processes. During cooling, the crystalline phase dominated over the disordered phase and increased ordering was accompanied with disordered phases of the coacervates to room temperature.

The melting points of the coacervates were found to be close expect for $\mathrm{C}_{12} \mathrm{TA}^{+} \mathrm{DS}^{-}$(results given in the supplementary section (table S3)).

3.2e Polarization microscopic study: The morphology of the solid phase of the coacervate (c.f. method section) was examined at $298 \mathrm{~K}$ by polarized microscopy (figure 5). For $\mathrm{C}_{10} \mathrm{TA}^{+} \mathrm{DS}^{-}$and $\mathrm{C}_{12} \mathrm{TA}^{+} \mathrm{DS}^{-}$, only needle shaped crystals were formed; for $n \geq 14$ flower-like structures as well as 


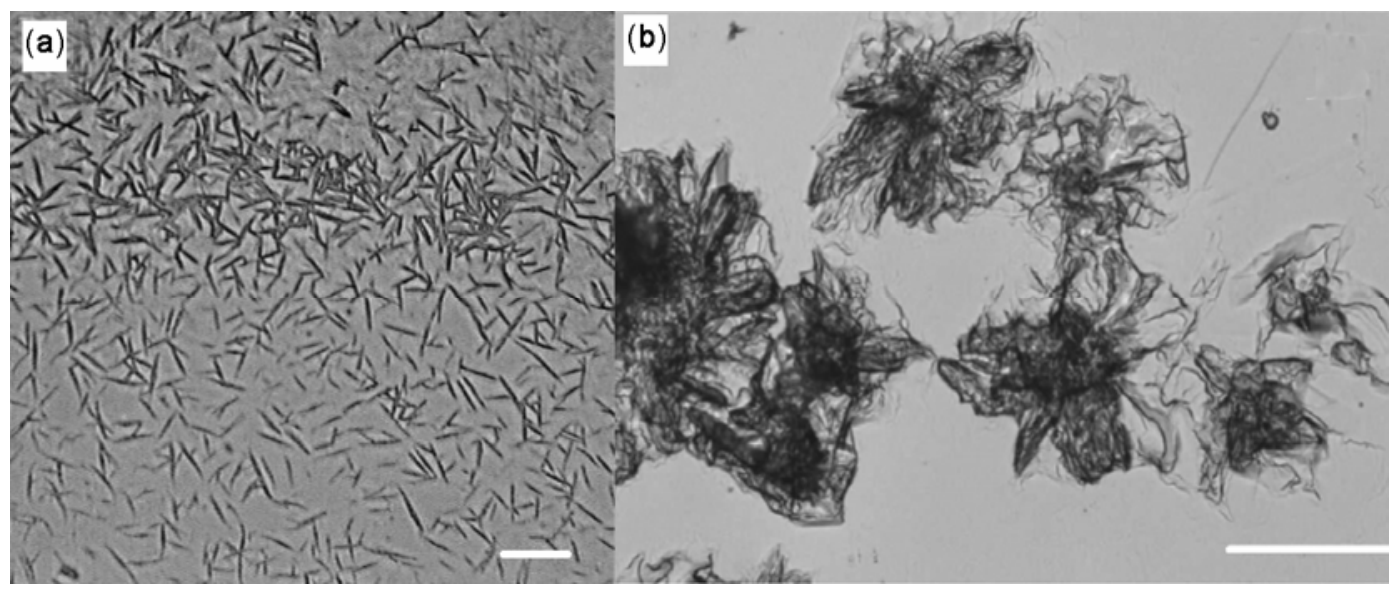

Figure 5. Polarizing microscopic images of IPAs at $298 \mathrm{~K}$. (a) $\mathrm{C}_{12} \mathrm{TA}^{+} \mathrm{DS}^{-}$and (b) $\mathrm{C}_{16} \mathrm{TA}^{+} \mathrm{DS}^{-}$. Scale bar $(\mu \mathrm{m}): 200(\mathbf{a}), 750$ (b).

needle shaped crystals were observed (additional figures were given in supplementary section (figure S4)). The structures became more complex and of larger sizes with increased hydrophobic chain length of the $\mathrm{C}_{n} \mathrm{TAB}$. The sizes of the needle shaped crystals increased with $C_{n} ; \mathrm{C}_{18} \mathrm{TA}^{+} \mathrm{DS}^{-}$produced most complex/agglomerated structures. The average length of the needle shaped crystals obtained for the coacervates is $55,118,110,150$, and $185 \mu \mathrm{m}$ for $\mathrm{C}_{10}, \mathrm{C}_{12}$, $\mathrm{C}_{14}, \mathrm{C}_{16}$, and $\mathrm{C}_{18} \mathrm{TA}^{+} \mathrm{DS}^{-}$, respectively. The size was found to be linearly increasing with the alkyl chain lengths (exception for $\mathrm{C}_{12} \mathrm{TA}^{+} \mathrm{DS}^{-}$). The crystals produced by $\mathrm{C}_{12} \mathrm{TA}^{+} \mathrm{DS}^{-}$were larger than that of $\mathrm{C}_{14} \mathrm{TA}^{+} \mathrm{DS}^{-}$due to the presence of more favourable hydrophobic interactions between the alkyl chains of equal lengths in the former. No previous studies on the polarization microscopic images of the $\mathrm{C}_{n} \mathrm{TA}^{+} \mathrm{DS}^{-}$are available in the literature.

\subsection{Coacervate properties}

The prepared and characterized coacervates $\left(\mathrm{C}_{n} \mathrm{TA}^{+} \mathrm{DS}^{-}\right)$were investigated in the following lines: solubility, interfacial behaviour and monolayer morphology. These are discussed below at some lengths in A, B and C.

3.3a Additive effect on the aqueous solubility of the coacervates: Aqueous solubility of the coacervates determined spectrophotometrically were found to be decreasing gradually with increasing $\mathrm{n}$ of $\mathrm{C}_{n} \mathrm{TA}^{+} \mathrm{DS}^{-}\left(56 \cdot 0,20 \cdot 2,15.5,9.90\right.$, and $5.40 \mu \mathrm{g} \mathrm{mL}^{-1}$ at $298 \mathrm{~K}$ for $n=10,12,14,16$ and 18 , respectively). The bile salts are biological detergents that have considerable biological significance. ${ }^{42}$ They can solubilize many important insoluble components like lipids, cholesterols, lecithin, etc. They are salts of $C_{22}$ to $C_{28}$ carboxylic acids with a cyclopentenophenanthrene molecule which contains a branched side chain of three to nine carbon atoms ending in the carboxyl group. In mammalian bile, they help solubilization of cholesterol forming mixed micelles with lecithin. The nature of solubility curves of the coacervates in $\mathrm{NaC}$ and $\mathrm{NaDC}$ environment at $298 \mathrm{~K}$ were similar for all the $\mathrm{C}_{n} \mathrm{TA}^{+} \mathrm{DS}^{-}$irrespective of $n$. The break points in the solubility vs [bile salt] plots (illustration given in supplementary section (figure S3)) corresponded to the CMCs of the bile salts. The solubility was found to be enhanced the in presence of bile salt micelles. The CMC thus found were $\sim 7.9$ and $\sim 4.2 \mathrm{mmol} \mathrm{dm}^{-3}$ for $\mathrm{NaC}$ and $\mathrm{NaDC}$, respectively at $298 \mathrm{~K}$ which agreed well with the literature report. ${ }^{42}$

Though cholesterol itself is poorly soluble in water, in presence of it, the aqueous solubility of the coacervates increased. $3.5-7 \mathrm{~mol} \%$ of cholesterol was found to be most effective; further increase in [cholesterol] decreased the solubility of the coacervates and even brought it down below the solubility of the pure one. In living cell membrane systems, the presence of a trace amount of cholesterol facilitates lipid-bilayer formation. ${ }^{34}$ Low concentration of cholesterol-assisted coacervate solubility to form vesicles which at higher concentration reversed. In presence of cholesterol, the maximum total solubility of the coacervates were found to be $72 \cdot 0,27 \cdot 1$, $22 \cdot 6,18 \cdot 0$, and $5.90 \mu \mathrm{g} \mathrm{mL}^{-1}$ at $298 \mathrm{~K}$ and the corresponding mole fraction of cholesterol were 0.064 , 
$0.039,0.066,0.071$ and 0.035 for $\mathrm{C}_{n} \mathrm{TA}^{+} \mathrm{DS}^{-}$with $n=10,12,14,16$ and 18 , respectively. In one of our previous studies, we found that the stability of a DPPC monolayer was dependent on the cholesterol content, whereby a $3.5-7.0 \mathrm{~mol} \%$ of cholesterol imparted maximum interfacial activity of DPPC monolayer. ${ }^{34}$ An antagonistic interaction was envisaged at higher concentration. The percent increase in solubility was highest for $\mathrm{C}_{10} \mathrm{TA}^{+} \mathrm{DS}^{-}$and was more or less similar for $C_{12}-\mathrm{C}_{16} \mathrm{TA}^{+} \mathrm{DS}^{-}$but it was lowest for $\mathrm{C}_{18} \mathrm{TA}^{+} \mathrm{DS}^{-}$. Similarity of the interactions between DPPC-cholesterol and $\mathrm{C}_{n} \mathrm{TA}^{+} \mathrm{DS}^{-}$-cholesterol was an indirect way to prove the lipid-mimicking properties of the studied coacervates.

3.3b Interfacial behaviour: The packing symmetry of the solvent spread monolayer of the coacervate at the air/water interface depended on the stoichiometry and the magnitude of the charged head groups and symmetry/dissymmetry in the precursors' chain length. The alkyl chains packed themselves in a way to maximize their van der Waals interaction forced the molecular packing at the air/water interface to be more compact resulting a lower molecular lift-off area. ${ }^{36}$ The $A_{\text {lift }}$ was the area when the surface pressure of the $\pi-A$ isotherm begins to rise. Figure 6 presents the surface pressure $(\pi)$ - area $(A)$ behaviours of the IPAs at the air/water interface. From the pattern of $\pi-A$ isotherm, important information like, molecular organization of the monolayer at the air/water interface, molecular interactions there, etc. could be evaluated. ${ }^{16,34,35}$

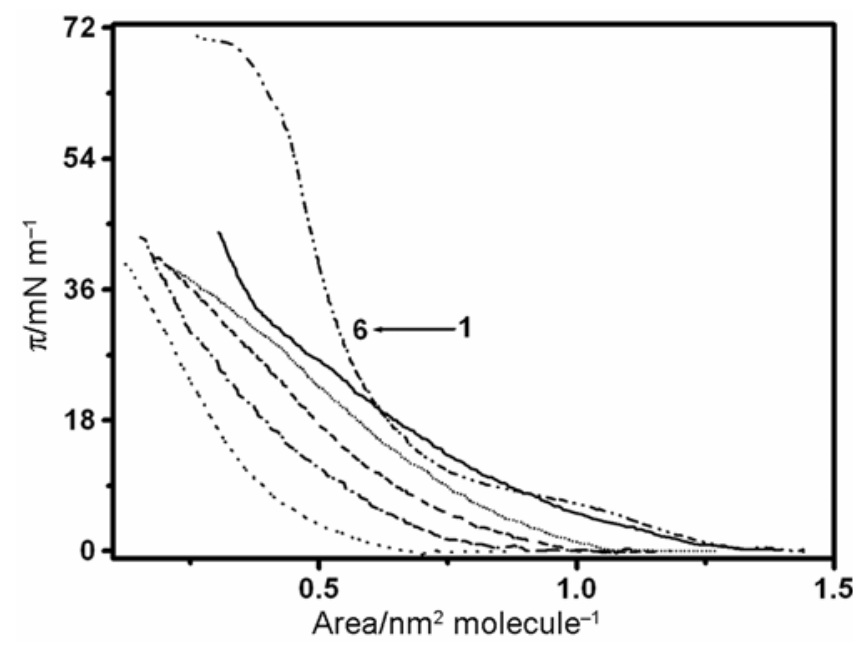

Figure 6. $\pi-A$ isotherms of IPAs at the air/water interface at $298 \mathrm{~K}$. Curves: 1: DPPC; 2: $\mathrm{C}_{10} \mathrm{TA}^{+} \mathrm{DS}^{-} ; 3$ : $\mathrm{C}_{12} \mathrm{TA}^{+} \mathrm{DS}^{-} ;$4: $\mathrm{C}_{14} \mathrm{TA}^{+} \mathrm{DS}^{-} ;$5: $\mathrm{C}_{16} \mathrm{TA}^{+} \mathrm{DS}^{-}$; and 6 : $\mathrm{C}_{18} \mathrm{TA}^{+} \mathrm{DS}^{-}$.
For better understanding of the phase transition in the monolayer, two-dimensional isothermal compressibility of the monolayer (the response of the film area to a compression stimulus) has been considered. The compression modulus $\left(C_{\mathrm{s}}^{-1}\right)$ is the reciprocal of the monolayer compressibility. ${ }^{35}$

$$
C_{\mathrm{S}}^{-1}=-A(\delta \pi / \delta A)
$$

A monolayer is classified ${ }^{43}$ on the basis of the maximal values of $C_{\mathrm{s}}^{-1}$ in the plots of $C_{\mathrm{s}}^{-1}$ vs $\pi$. A maximum compressibility modulus value in the range of $12.5-50 \mathrm{mN} \mathrm{m}^{-1}$ corresponds to the liquidexpanded state; whereas such values in the range of $50-100 \mathrm{mN} \mathrm{m}^{-1}$ stands for the liquid state. Higher values in the range of $100-250 \mathrm{mN} \mathrm{m}^{-1}$ correspond to the liquid-condensed state; and finally, $C_{\mathrm{s}}^{-1} \max >$ $250 \mathrm{mN} \mathrm{m}^{-1}$ means a solid-like state. In this study, $C_{\mathrm{s}}^{-1}$ were obtained by processing the $\pi-A$ isotherm data points using equation (1). The error limit of $A_{\text {lift }}$ was $\pm 0.1 \mathrm{~nm}^{2}$ molecule ${ }^{-1}$, and that of $C_{\mathrm{s}}^{-1}$ was $\pm 0.1 \mathrm{mN} \mathrm{m}^{-1}$

The studied IPA components were individually soluble in water, and did not form Langmuir monolayer at the air/water interface, but instead they formed micelle in the bulk. $\mathrm{C}_{18} \mathrm{TAB}$ was an exception, due to its lower aqueous solubility; it formed close-packed monolayer at the air/water interface ${ }^{39}$ with a $A_{\text {lift }}=0.81 \mathrm{~nm}^{2}$ molecule ${ }^{-1}$. With the variation of the hydrophobic chain length, the formed IPA tended to show differences in $\pi-A$ isotherm behaviour which was governed by the relative strength of intra-monolayer hydrophobic interactions. The observed $A_{\text {lift }}$ values $(0.68,0.83,1.00,1.08$, and $1.23 \mathrm{~nm}^{2}$ molecule ${ }^{-1}$ for $\mathrm{C}_{n} \mathrm{TA}^{+} \mathrm{DS}^{-}$with $n=10,12$, 14,16 , and 18 , respectively) were found to be linearly increased with $n$ (alkyl chain length of $\mathrm{C}_{n} \mathrm{TAB}$ ). For DPPC, the $A_{\text {lift }}$ value $\left(1.28 \mathrm{~nm}^{2}\right.$ molecule $\left.{ }^{-1}\right)$ was close to that of $\mathrm{C}_{18} \mathrm{TA}^{+} \mathrm{DS} \mathrm{S}^{-}$. In our earlier findings, ${ }^{16}$ similar trend in $A_{\text {lift }}$ for $\mathrm{C}_{n} \mathrm{TA}^{+} \mathrm{DS}^{-}(n=12,14$, and 16) were also observed. A hysteresis in the isotherm cycle of the catanionic surfactants was observed which meant that the process was irreversible, i.e. loss of material from the interface occurred during compression. The $\mathrm{C}_{\mathrm{s} \max }^{-1}$ of the coacervates for the $\mathrm{C}_{n} \mathrm{TA}^{+} \mathrm{DS}^{-}$were $34.87,30.91,33.81,35.65$, and $49.75 \mathrm{mN} \mathrm{m}^{-1}$ for $n=10,12,14,16$, and 18 , respectively whereas DPPC gave a higher $\mathrm{C}_{\mathrm{s}}^{-1} \max$ $\left(129.5 \mathrm{mN} \mathrm{m}^{-1}\right)$. With increase in the alkyl chain length of $\mathrm{C}_{n} \mathrm{TAB}$, the $\mathrm{C}_{\mathrm{S}}^{-1}$ max was found to increase (following a two degree polynomial equation with 

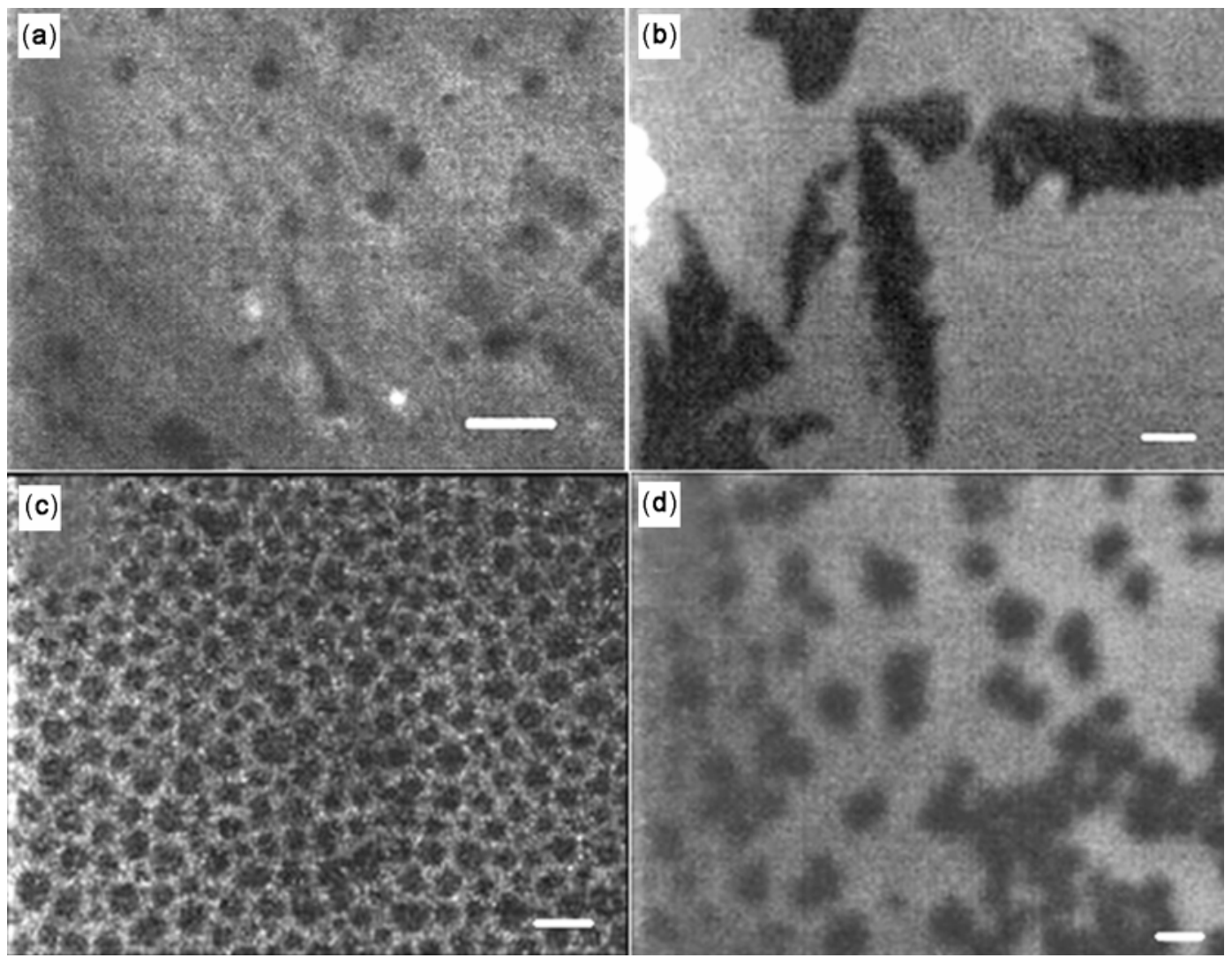

Figure 7. Epifluorescence microscopy images of solvent spread monolayer of $\mathrm{C}_{18} \mathrm{TA}^{+} \mathrm{DS}^{-}$ (a and b) and DPPC (c and d) doped with $1 \mathrm{~mol} \%$ NBD-PC at different $\pi$ at the air/water interface at $298 \mathrm{~K} . \pi\left(\mathrm{mN} \mathrm{m}^{-1}\right): 25(\mathbf{a}, \mathbf{c})$, and $35(\mathbf{b}$, d). Scale bar: $200 \mu \mathrm{m}$. (a) circular (average radius $=30 \mu \mathrm{m})$; (b) fern-leaf like structures.

$\left.R^{2}=0.957\right) . \mathrm{C}_{\mathrm{S}}^{-1} \max$ was observed at $16 \cdot 3,39.0$ and $63.9 \mathrm{mN} \mathrm{m}^{-1}$, respectively for $\mathrm{C}_{10}-\mathrm{C}_{16} \mathrm{TA}^{+} \mathrm{DS}^{-}$, $\mathrm{C}_{18} \mathrm{TA}^{+} \mathrm{DS}^{-}$and DPPC. The $\mathrm{C}_{\mathrm{S} \text { max }}^{-1}$ observed by Panda et al $l^{16}$ for $\mathrm{C}_{12}-\mathrm{C}_{16} \mathrm{TA}^{+} \mathrm{DS}^{-}$were also at about $16 \mathrm{mN} \mathrm{m}^{-1}$ and the values were comparable with that of ours.

The epifluorescence images of coacervates and DPPC at the air/water interface showed interesting features. For DPPC, the average circular radius of the domains was $67 \mu \mathrm{m}$ (figure $7 \mathrm{c}$ ) whereas that for $\mathrm{C}_{18} \mathrm{TA}^{+} \mathrm{DS}^{-}$was about half this value $(30 \mu \mathrm{m})$ at $\pi=25 \mathrm{mN} \mathrm{m}^{-1}$ (figure 7a).

At $\pi=35 \mathrm{mN} \mathrm{m}^{-1}$, the domains of DPPC (figure 7d) were agglomerated. DPPC were taken as baseline as it is a well-studied system whose monolayer morphology is well-known. ${ }^{19} \mathrm{C}_{18} \mathrm{TA}^{+} \mathrm{DS}^{-}$showed fern-leaf like structures at that surface pressure. Panda et $a l^{16}$ also reported similar types of results. $\mathrm{C}_{14}$ and $\mathrm{C}_{16}$ also produced similar types of images. Such domain formations were not obtained for $\mathrm{C}_{10}$ and $\mathrm{C}_{12}$ representatives.

\section{Conclusions}

The ternary system $\mathrm{C}_{n} \mathrm{TAB} / \mathrm{SDS} / \mathrm{H}_{2} \mathrm{O}$ produced different phases and the complexity increased with decreasing alkyl chain length of $\mathrm{C}_{n} \mathrm{TAB}$. During titration, gelation of the solution occurred in case of $n \leq 12$. Aqueous solubility of the coacervates decreased with increasing alkyl chain length of their cationic part. The formed IPAs were like noncovalent bilayers that aggregated in solution to yield vesicles. 3.5-7 mol\% of cholesterol imparted maximum solubility to the coacervates; further increase in cholesterol content had opposite effect on solubility. The bile salts also increased the solubility of the coacervates as their micelles could fairly stabilize/solubilize the IPAs by way of forming mixed aggregates. The formation of ionic bond in the coacervates was confirmed by ${ }^{1} \mathrm{H}-\mathrm{NMR}$ and FTIR spectra. The appearance of $00 l \mathrm{X}$-ray diffraction lines at a regular intervals supported lamellar structure of the coacervates, where the spacing between 
two successive $00 l$ lines $(\Delta 2 \theta)$ decreased linearly with increasing $C_{\mathrm{n}}$. The DSC thermogram produced large hysteresis, where the peak corresponding to the solid to liquid crystal transition (showed splitting for $C_{n}>12$ ) was associated with higher enthalpy change than that of the melting peaks. All the IPAs were found to produce needle-shaped crystals except $\mathrm{C}_{18} \mathrm{TA}^{+} \mathrm{DS}^{-}$(which formed large non-specific elongated structures). At the air/water interface, the IPA films were in liquid-expanded state and compression produced with minorly polydispersed spherical domains that grew in size with increased surface pressure; fern-leaf like structures were appeared at higher state of compression for $\mathrm{C}_{\mathrm{n}} \geq 14$.

The anomalous behaviour of $\mathrm{C}_{12} \mathrm{TA}^{+} \mathrm{DS}^{-}$from the other $\mathrm{C}_{\mathrm{n}} \mathrm{TA}^{+} \mathrm{DS}^{-}$were because of matching of the hydrophobic chain lengths of cationic and anionic surfactants. The $\mathrm{C}_{n} \mathrm{TA}^{+} \mathrm{DS}^{-}$showed similar physicochemical properties like DPPC, so they are prospective replacer for the lipid. To explore their lipidmimicking properties further studies on the coacervates by AFM, TEM and other techniques are warranted.

\section{Supplementary information}

For supplementary information see www.ias.ac.in/ chemsci website.

\section{Acknowledgements}

K M thanks Council of Scientific and Industrial Research (CSIR), Govt. of India, New Delhi, for a Senior Research Fellowship. S P M thanks Indian National Science Academy for an Honorary Scientist position. The authors thank the Department of Science and Technology (DST), Govt. of India, New Delhi, for funding; Department of Metallurgical Engineering, J.U. for XRD study; M Ali, Department of Chemistry, University of North Bengal, for DSC measurements and Dr. D C Pal, Department of Geological Sciences, Jadhavpur University for polarization microscopic study.

\section{References}

1. Kaler E W, Murthy A K, Rodriguez B E and Zasadzinski J A N 1989 Science 2451371

2. Herrington K L, Kaler E W, Miller D D, Zasadzinski J A N and Chiruvolu S 1993 J. Phys. Chem. 9713792

3. Zhu Z, Xu H, Liu H, Gonzalez Y I, Kaler E W and Liu S 2006 J. Phys. Chem. B110 16309
4. Touitou E and Godin B 2003 Crit. Rev. Ther. Drug Carrier Sys. 2063

5. Bramer T, Dew N and Edsman K 2007 J. Pharm. Pharmacol. 591319

6. Hentze H P, Raghavan S R, McKelvey C A and Kaler E W 2003 Langmuir 191069

7. Rädler J O, Koltover I, Salditt T and Safinya C R 1997 Science $\mathbf{2 7 5} 810$

8. Lasic D D 1998 Trends Biotechnol. 16307

9. McKelvey C A, Kaler E W, Zasadzinski J A N, Coldren B and Jung H T 2000 Langmuir 168285

10. Caruso F 2000 Chem. Eur. J. 6413

11. Pasc-Banu A, Stan R, Blanzat M, Perez E, RicoLattes I, Lattes A, Labrot T and Oda R 2004 Colloids Surf. A 242195

12. Israelachvili J N 1991 Intermolecular and surface forces (London: Academic Press) 2nd edn, Chapter 17, p. 370

13. Maiti K, Bhattacharya S C, Moulik S P and Panda A K 2010 Colloid Surf. A355 88

14. Tanford C 1980 The hydrophobic effect: formation of micelles and biological membranes (New York: Wiley and Sons)

15. Clavero E, Rodriguez J and Laria D 2007 J. Chem. Phys. 127124704

16. Panda A K, Possmayer F, Petersen N O, Nag K and Moulik S P 2005 Colloids Surf. A 264106

17. Lee Y L, Yang Y C and Shen Y J 2005 J. Phys. Chem. B109 4662

18. Chou T-H, Lin Y-S, Li W-T and Chang C-H $2008 \mathrm{~J}$. Colloid Interface Sci. 321384

19. Dastis M, Rojo N, Alsina M A, Haro I, Panda A K and Mestres C 2004 Biophys. Chem. 109375

20. Prenner E, Honsek G, Honig D, Mobius D and Lohner K 2007 Chem. Phys. Lipids 145106

21. Nag K, Fritzen-Garcia M, Devraj R and Panda A K 2007 Langmuir 234421

22. Zasadzinski J A N and Hansma P K 1990 Annal. NY Acad. Sci. $\mathbf{5 8 9} 476$

23. Safran S A $1999 A d v$. Phys. 48395

24. Chevalier Y and Zemb T 1990 Rep. Prog. Phys. 53 279

25. Kaler E W, Herrington K L, Miller D D and Zasadzinski J A N 1992 Structure and dynamics of strongly interacting colloids and supramolecular aggregates in solution (eds) Chen $\mathrm{S} \mathrm{H}$, Huang J S and Tartaglia P (Dordrecht, The Netherlands: Kuwler Academic) pp. 571-577

26. Marques E F, Regev O, Khan A and Lindman B 2003 Adv. Colloid Interface Sci. 100-102 83

27. Rodriguez J, Clavero E and Laria D $2005 \mathrm{~J}$. Phys. Chem. B109 24427

28. Vollhardt D, Melzer V and Fainerman V 1998 Thin Solid Films 327-329 842

29. Viseu M I, Da Silva A M G and Costa S M B 2001 Langmuir 171529

30. Kaler E W, Herrington K L, Murthy A K and Zasadzinski J A N 1992, J. Phys. Chem. 966698

31. Eastoe J, Rogueda P, Shariatmadari D and Heenan R 1996 Colloid Surf. A 117215 
32. Persson G, Edlund H, Hedenstro"m E and Lindblom G 2004 Langmuir 201168

33. Tomasic V, Popovic S, Tusek-Bozic L, Pucic I and Filipovic-Vincekovic N 1997 Ber. Bunsenges. Phys. Chem. 1011942

34. Panda A K, Hume A, Nag K, Harbottle R R and Petersen N O 2003 Ind. J. Biochem. Biophys. 40114

35. Panda A K, Nag K, Harbottle R R, Rodriguez-Capote $\mathrm{K}$, Veldhuizen R A W and Possmayer F $2004 \mathrm{Am}$. J. Res.Cell Mol. Biol. 30641

36. Safran S A, Pincus P and Andelman D 1990 Science 248354

37. Viseu M I, Edwards K, Campos C S and Costa S M B 2000 Langmuir 162105
38. Brasher L L, Herrington K L and Kaler E W 1995 Langmuir 114267

39. Maiti K, Chakraborty I, Bhattacharya S C, Panda A K and Moulik S P 2007 J. Phys. Chem. B111 14175

40. Ulmius J and Wennerstrom H 1977 J. Magn. Reson. 28309

41. Tomasic V, Popovic S and Filipovic-Vincekovic N 1999 J. Colloids Interface Sci. 215280

42. Jana P K and Moulik S P 1991 J. Phys. Chem. 95 9525

43. Davis J T and Rideal E K 1963 Interfacial Phenomenon (New York: Academic Press)

44. Basu Ray G, Chakraborty I, Ghosh S, Moulik S P and Palepu R 2005 Langmuir 2110958 